\title{
Perlmutt: Das schlaue Material
}

\author{
Perlmutt fasziniert den Menschen seit jeher. Es gibt Muschelschalen ihr schillerndes \\ Aussehen und schützt das Tier vor Fressfeinden und anderen Bedrohungen. Seit über 80 \\ Jahren rätseln Wissenschaftler, woher die außergewöhnliche Härte von Perlmutt stammt. \\ Nun hat ein internationales Team aus den Bereichen Material- und Geowissenschaften sowie \\ Biologie, an dem auch Wissenschaftler der Friedrich-Alexander-Universität Erlangen-Nürn- \\ berg (FAU) beteiligt sind, das Geheimnis gelüftet. Mit den Ergebnissen könnte eine neue \\ Generation von bruchfesten keramischen Materialien entwickelt werden.
}

Forscher kennen den Aufbau von Perlmutt seit Jahrzehnten - es besteht aus mikroskopisch kleinen „Ziegelsteinen“ eines Minerals namens Aragonit, das aus einfachem Kalk besteht, und einem "Mörtel“ aus organischem Material. Diese Anordnung verleiht zwar generell Festigkeit, aber Perlmutt ist weitaus widerstandsfähiger als seine einzelnen Komponenten vermuten lassen. In ihrem Experiment übte das Team unter einem Elektronenmikroskop auf die Schalen Druck aus und beobachte in Echtzeit, was passierte: Die Verformung der Struktur war komplexer als gedacht (Bild 1).

„Zentral für die von uns beobachteten Eigenschaften ist eine Kompositstruktur auf der Nanoskala, die das keramische Material Kalk eng mit Proteinen und anderen organischen Bestandteilen verwebt. Das gelingt der Muschel, indem sie kleinste Kalkpartikel zu Plättchen zusammenlagern lässt, ein Prozess, den wir derzeit genau untersuchen, um die fabelhaften Eigenschaften eines Tages auch synthetisch abbilden zu können", erklärt Prof. Dr. Stephan Wolf, Juniorprofessor für Biomimetische Materialen und Prozesse am Lehrstuhl für Glas und Keramik der FAU.

Bildlich gesprochen funktioniert das so: Die "Ziegelsteine“ sind tatsächlich mehrseitige „Plättchen“, die nur wenige hundert Nanometer groß sind. In der Regel bleiben

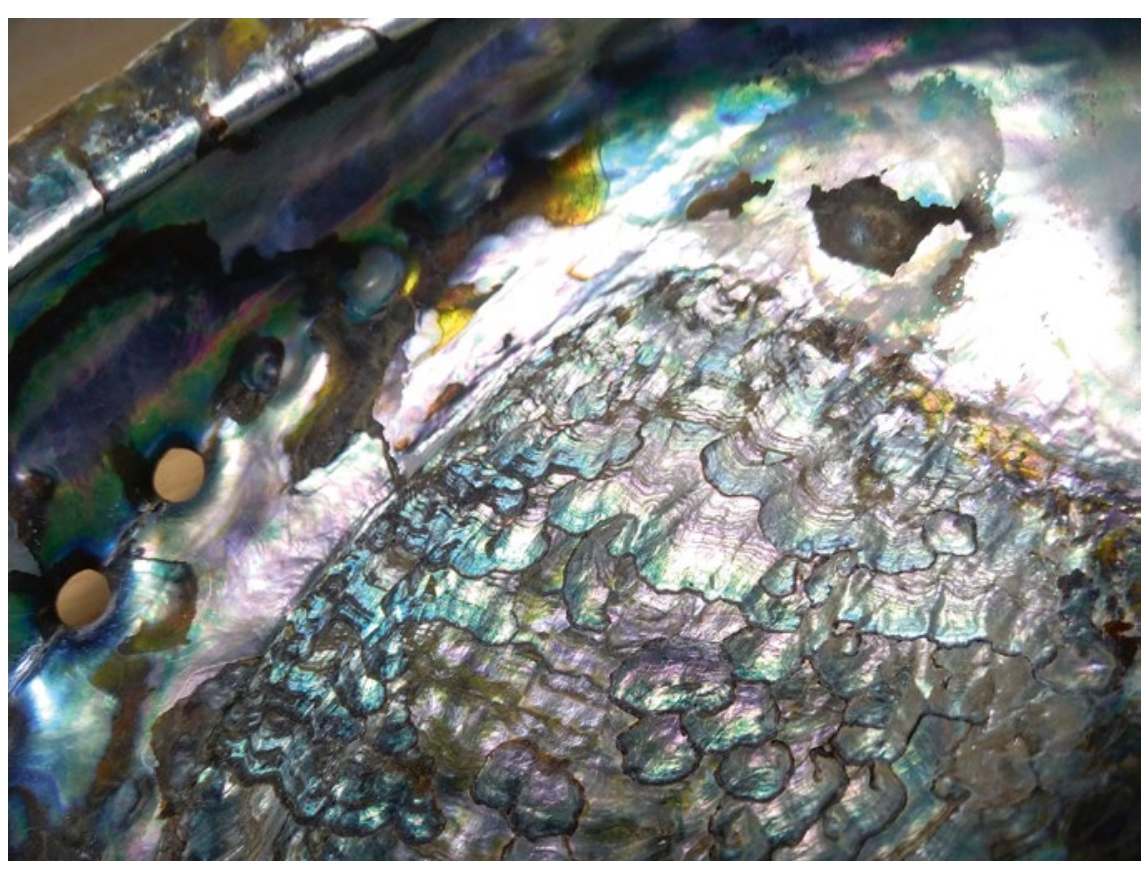

Bild 1 FAU-Wissenschaftler haben zusammen mit internationalen Kollegen das Rätsel um die Härte von Perlmutt (im Bild das Perlmutt einer Abalone-Schnecke) geknackt. (@ Stephan E. Wolf) diese Plättchen getrennt, in Schichten angeordnet und von einer dünnen Schicht organischen „Mörtels“ gepolstert. Bei Belastung der Muschelschalen wird der "Mörtel“ jedoch beiseite gequetscht, die "Plättchen“ verhaken sich so sehr, dass sie gemeinsam die Belastung tragen und so daran nicht zerbrechen. Wird der Druck weggenommen, springt die Struktur in ihre alte Form zurück, ohne an Festigkeit oder Elastizität zu verlieren. Diese Eigenschaft ist außergewöhnlich, denn: Selbst die fortschrittlichsten Materialien, die von Menschen entworfen wurden, können das nicht. Kunststoffe können beispielsweise durch einen Aufprall zurückspringen, verlieren jedoch jedes $\mathrm{Mal}$ etwas an Festigkeit. Perlmutt hingegen verlor in den Experimenten bei wiederholten Schlägen kaum etwas von seiner Widerstandsfähigkeit. „Es ist unglaublich, wie eine Muschel - die nicht gerade für ihre Intelligenz gerühmt wird - so ein komplexes Material generiert, das über viele Längenskalen strukturiert ist", sagt Prof. Hovden von der University of Michigan und Leiter der Studie.

Ihre Ergebnisse erlauben es Materialwissenschaftlern, eine neue Generation von bruchfesten keramischen Materialien zu entwickeln, die widerstandsfähig auf Belastungen reagieren, Anforderungen wie sie für Alltags- oder Spezialanwendungen in der Medizintechnik auftreten, zum Beispiel für Zahn- und Knochenimplantate.

Kontakt: Friedrich-Alexander-Universität Erlangen-Nürnberg, Institut für Glas und Keramik, www.ww.tf.fau.de 